\title{
Innovation Management and International standards - how they Relate to Research Institutes
}

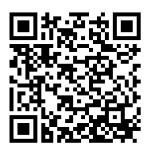

\author{
Ida Srdić* \\ Innovation Manger, Ruđer Bošković Institute, Croatia
}

Submission: July 02, 2020; Published: August 13, 2020

${ }^{*}$ Corresponding author: Ida Srdić, Innovation Manger, Ruđer Bošković Institute, Bijenička 54, Croatia

Keywords: Innovation; Organisation; Communication; Business Improvement; Governance; Management

\section{Introduction}

Standards are, according to dictionary definitions, principles of propriety, honesty and integrity. "A standard is an agreed way of doing something. It could be about making a product, managing a process, delivering a service or supplying materials - standards can cover a huge range of activities undertaken by organisations and used by their customers." (Business Improvement and Standards https://www.bsigroup,com). They are important tools because they provide people and organisations with the foundations for mutual understanding, and are used to facilitate communication, measurement, commerce and manufacturing. Also, they are enabling companies to comply with relevant laws and regulations, and they help to speed up the introduction of innovative products to market, providing interoperability between new and existing products, services and processes. The new ISO 56000 series of International Standards is aimed at providing organizations with guidelines and processes that enable them to get the most out of their innovation projects. ISO56002 is a key document in the new series of International Standards for managing innovation. It is important that an innovation standard is not prescriptive, but, instead aims to provide a framework for managing innovation to get the best out of idea [1-2].

It might seem counter-intuitive that the innovation could be served by the introduction of formal processes, governance, and even standard, especially for organisations that are not businessoriented, such as research institutes. But, by 'doing innovation properly' we can speak about the consensus for innovation best practices, making innovation a measurable unit and validating it in a way that reflects the values of the innovators and their organization[3-4]. Let us see how IS056002 can be aligned with research organisations where the main activity is scientific research. It can be said that the main "product" is shared knowledge, often presented in a reputable scientific paper, which is the process that already has the agreement and the approval of the appropriate scientific community. Is the standard necessary, and can it be sufficiently generic to be applicable in the diverse communities of research institutes?

\section{Generic approach}

In the scope of the ISO56002 authors used generic approach intended to be applicable to:

i. all types of organisations, regardless of type, sector or size

ii. all types of innovations, e.g. product, service, process, model, and method, ranging from incremental to radical

iii. all types of approaches, e.g. internal and open innovation, user-, market-, technology-, and design driven innovation activities.

In the era of tailored made solutions someone could ask a question: How an innovation management can be implemented in a generic fashion? Would this be more like implementing an ordinary management system with a few buzzwords corresponding to the innovation eco-system or it would claim generic approach and in fact be tailor-made for one type of organisation close to the experience and working environment of standard's authors? ISO 56002 does not describe detailed activities within the organisation, but rather provides guidance at a general level. It does not prescribe any requirements or specific tools or methods for innovation activities. However, in Innovation management framework Figure 1. we can see well known PlanDo-Check-Act (PDCA) cycle starting with very well-defined prerequisites for the "Context of the organisation" (explained in 
part 4 of the standard) and "Opportunities intent", as an input for the whole cycle. If you ever worked with a scientist in a research institute or in an educational organisation with professors then you know that neither the "Context of the organisation", nor the "Opportunities intent" are in correlation with the innovations. Innovations can come out of scientific research but more like a by-product then a planned result. To implement a performance evaluation connected with innovations in such environment could be counterproductive [5]. Nevertheless, in accordance with the standard, an innovation management system is a set of interrelated and interacting elements, aiming for the realization of value Figure 2. To follow the activities determined in the chart Plan-Do-Check-Act (PDCA) cycle the organisation should regularly determine areas of opportunities and/or determine external and internal issues that are relevant to its purpose. The standard here assumes that the PDCA cycle in innovation management system is connected with organisational performance evaluation system and that the innovation value creation is connected with support and operations entities in organisation. On the other hand, it separate validation of innovative concepts in operations (8) from performance evaluation (9) in PDCA cycle automatically creating parallel processes: one to evaluate innovative concept and other to evaluate the innovation management system performance itself which is good and make it possible to set independently the set of innovation performance indicators, quantitative or qualitative.

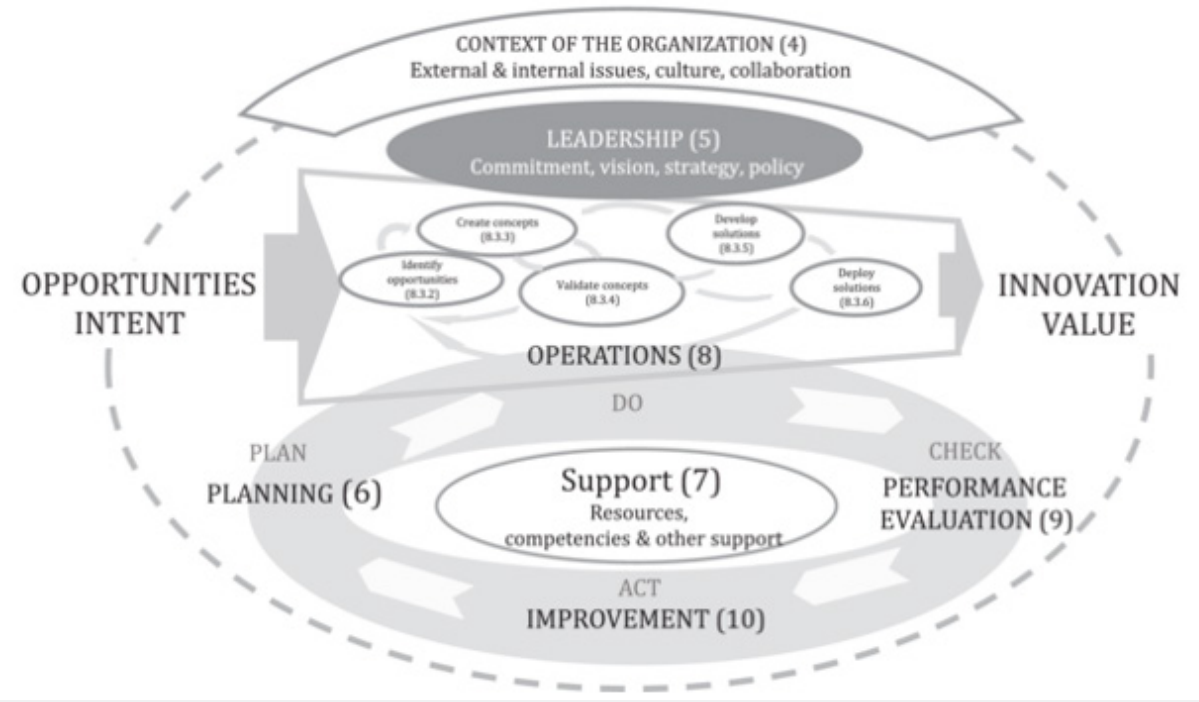

Figure 1: ISO 56002:2019 Representation of the framework of the innovation management system.

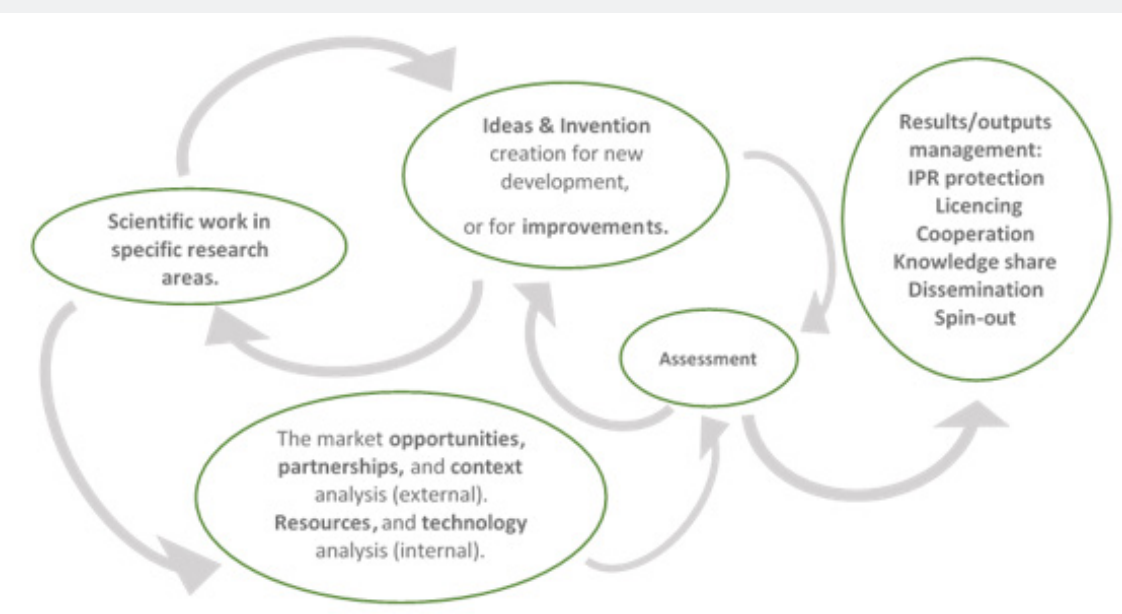

Figure 2: Innovation management process in research organization. 


\section{The standard proposes a balance of:}

i. input-related indicators, e.g. number of ideas, number of innovation initiatives, value creation potential of ideas, new sources of knowledge, new insights, resources, and competence;

ii. throughput-related indicators, e.g. speed of experimentation, learning and development, number or ratio of employees, managers or users involved or trained, effectiveness of collaboration and relationships, new tools and methods adopted, time to profit, time to market, engagement level, and brand awareness;

iii. output-related indicators, e.g. number or ratio of ideas implemented, return on innovation investment, revenue and profit growth, market share, ease of use, satisfaction, rate of innovation diffusion, organizational renewal and transformation, social and sustainability benefits, cost savings, rate of learning, intellectual property, new users, and image.
The organization can use comparisons with other similar organizations when monitoring and evaluating performance. By using only, the set of parameters related to the research organisations we can avoid a trap of starting with customer needs and market opportunities and calculating the number of new ideas to support them. Instead we can start with research results, propose the commercial stream through market analysis and propose partnership for further commercialization, and in evaluation we can use new sources of knowledge and knowledge share for indicators aligning it with institute's primary goal. In such way, in the area of PDCA cycle, the standard is sufficiently generic to be applicable in research institute. Although, the actions to connect PDCA cycle with organisational performance evaluation system, and the innovation value creation with support entities in organisation need to take place. Of course, under the assumption that the research institute has innovation management support capabilities [6-8].

\section{Innovation processes}

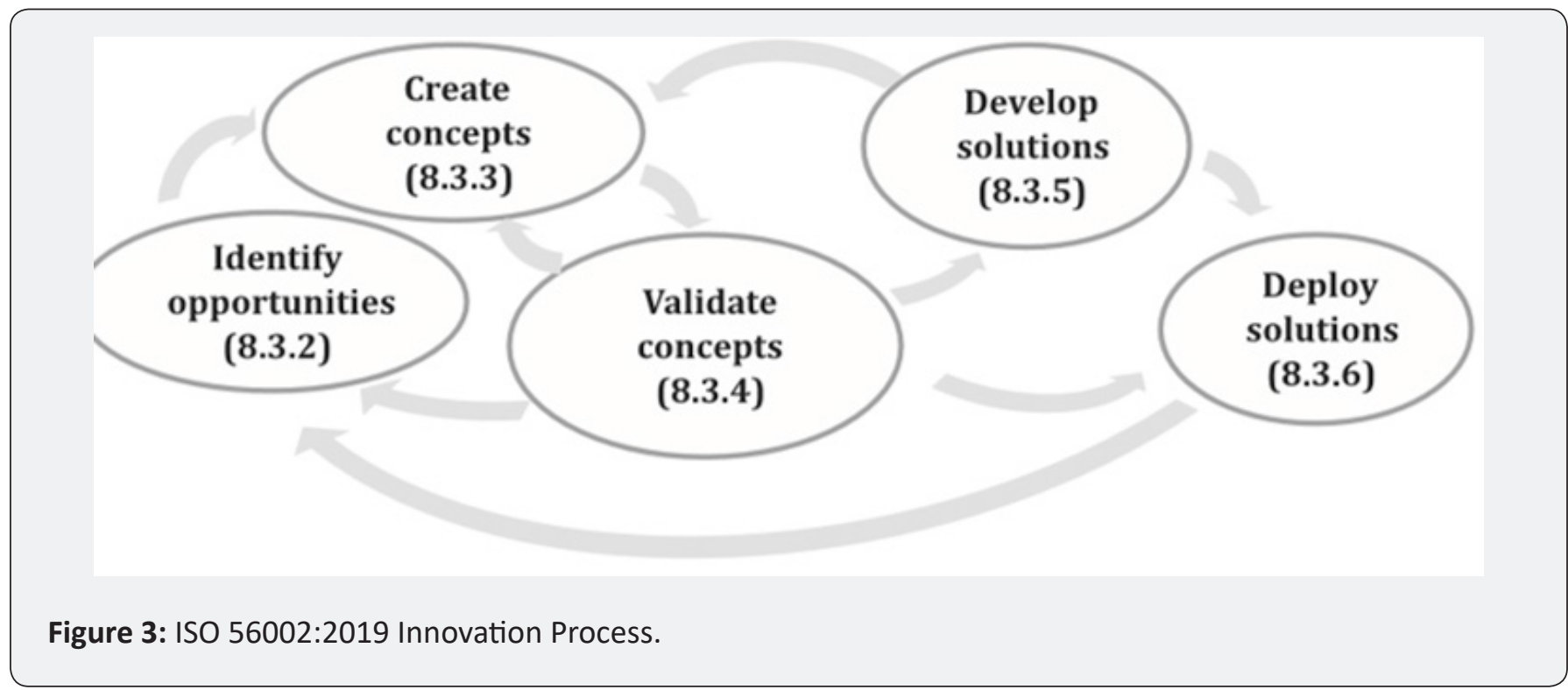

For an implementation of innovation management standard, the application of innovation process is fundamental. In dictionary definitions, the process is defined as a set of activities that interact to produce a result; it may occur once-only or be recurrent or periodic. In the standard, innovation process is defined as a business process with activities that produce a specific solution for customers out of innovative concept, Figure 3. It is comparable with similar business processes like for example Sage's innovation process Figure 4. For example, one of their products is actual for hospitalized people. Sage is offering a solution to prevent hospitalacquired pneumonias (HAP), including ventilator-associated pneumonia (VAP) that often start in the oral cavity. Bacteria, including dental plaque, can colonize in the oropharyngeal area, and these pathogens can be aspirated into the lungs, causing infection. Sage developed "Q•Care Oral Cleansing \& Suctioning
System" that have helped reduce the risk of hospital-acquired pneumonia, Figure 5 . They claim that $88 \%$ of the hospital's oral care market is trusted to Sage oral care. On the other hand, innovation in research institute is usually improvement of a method for further research and discoveries. For example, the Time-of-flight Elastic Recoil Detection Analysis (TOF-ERDA) setup at the Ruđer Bošković Institute is used for quantitative elemental depth profiling of all elements in the samples. After development and implementation of TOF-ERDA method, as an Ion Beam Analysis (IBA) method in material's science, back in 2010, scientists were able to obtain elemental concentration of all elements in the sample, including hydrogen, in one measurement in approximate duration of 20 min. The efficiency of hydrogen detection was improved for more than $50 \%$ compared with other available similar setups in the world. Also, hydrogen depth profiling with a $15 \mathrm{~N}$ nuclear reaction 


\section{Annals of Social Sciences \& Management studies}

needs numerous measurements, and in TOF-ERDA all elements (including hydrogen isotopes) are separated and analysed in a single measurement. The unique characteristics of this technique is the element depth profiling of a wide range of elements, from hydrogen to mid Z elements with similar sensitivity and depth resolution as can be seen on Figure 6(a) \& 6(b). Concentrations of 0,1 at. $\%$ can easily be detected. Depth analysis is limited to maximum $500 \mathrm{~nm}$ below the surface (depending on the sample matrix composition) making it best for usage in semiconductor and optics thin film industry. The innovative method at RBI is using special thin DLC foils, coated with LiF to improve emission of electrons from the foil after passing of ion. For more information please visit web page with references https://www.irb.hr/eng/ Divisions/Division-of-Experimental-Physics/Laboratory-for-ionbeam-interactions/Articles/toferda. Was this extremely valuable method superior creating innovative value for RBI? The answer is, yes. Was it make RBI more competitive in a service market for optics and semiconductor thin films production companies? The answer is, no. Let us analyse why?

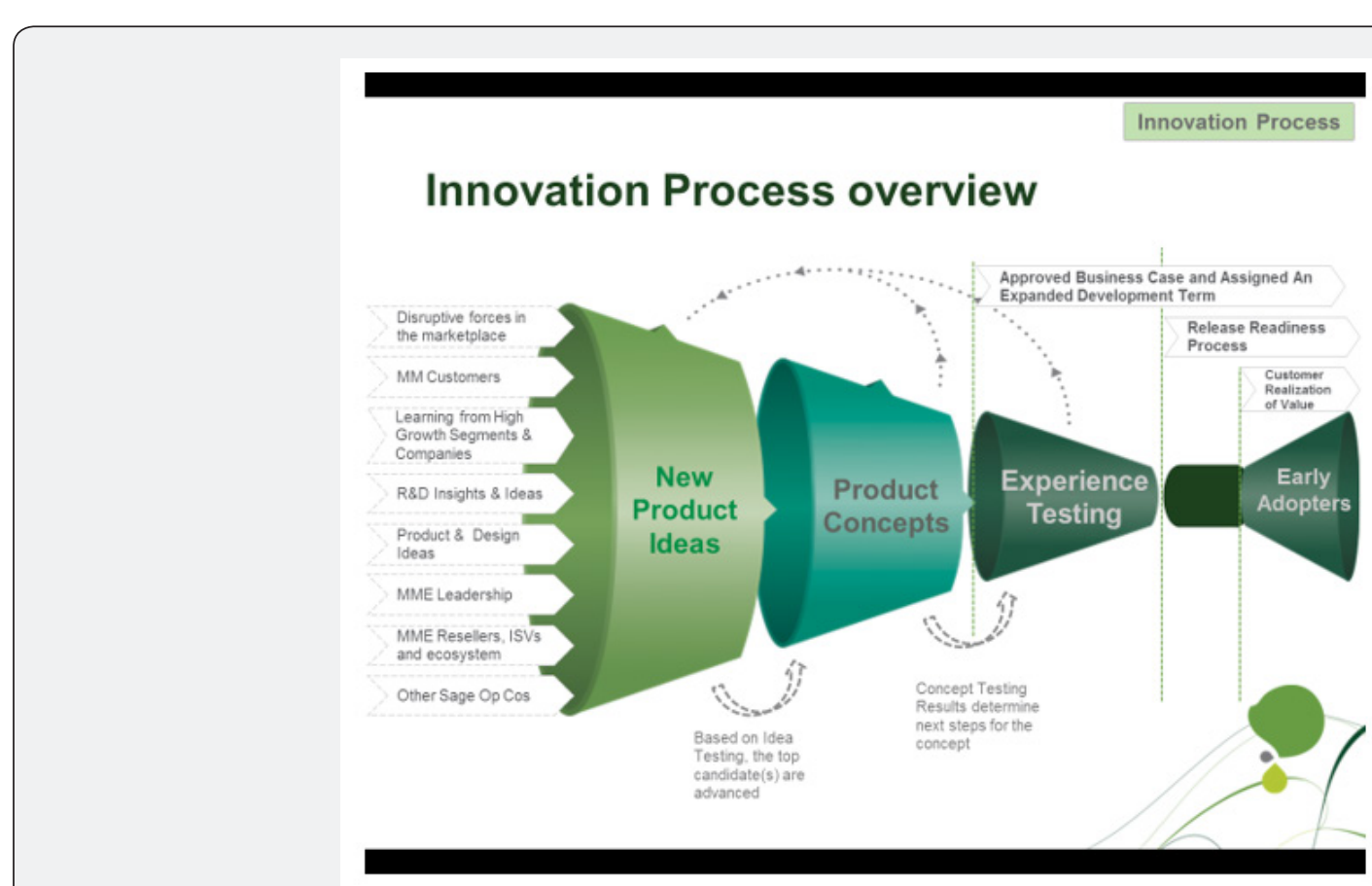

Figure 4: Sage's Innovation Process.

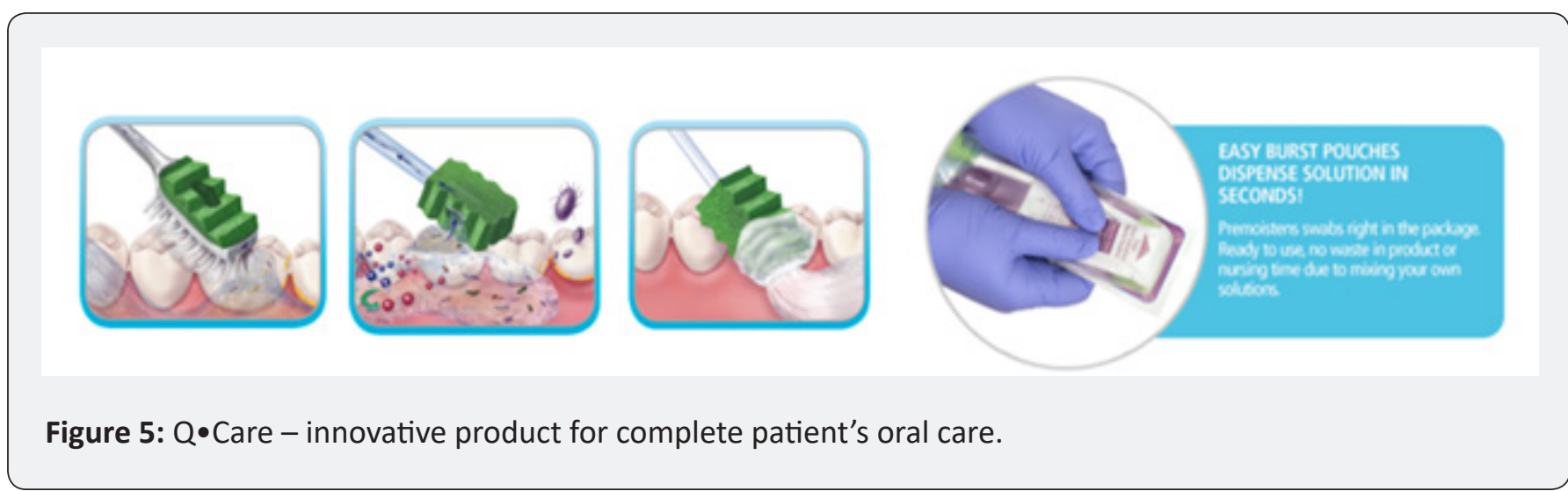

When TOF-ERDA was developed there was no innovation management at RBI and subsequently three out of five actions in innovation management process, Figure 2, never took place: (1) market opportunities, partnerships, context, resources, and technology analysis, (2) invention assessment, and (3) results management. Consequently, PDCA cycle didn't cycle. The goal for the introduction of this superior method was to enable research with such innovative equipment and then to share knowledge. Acquired good position in the research community enabled further research, also, for foreign researches. Several other institutes, in 


\section{Annals of Social Sciences \& Management studies}

the forthcoming years, purchase this valuable equipment together with know-how knowledge. The goal set at the beginning was accomplished [9]. The first action in the innovation management would show, through market analysis, that semiconductor and thin-film optics industry does not exist in the country. Subsequently, it is very difficult and time consuming to market it for the industries abroad. To prove that, the current commercial customers come without any marketing activities but slowly and in low number through word of mouth. Would this result from the market analysis together with ROI in the unexpectable time frame stop the development and implementation of the TOF-ERDA and prevent this valuable research activity? No, it would not. We recall that the innovation performance indicators would be adjusted with research institute goals at the first place. The only difference would be that the appropriate technology transfer entities, on the country level, will be included at the beginning to make this even more successful story (in business values) [10]. Of course, under the assumption that efficient and well liaison technology transfer entities exist in the country.
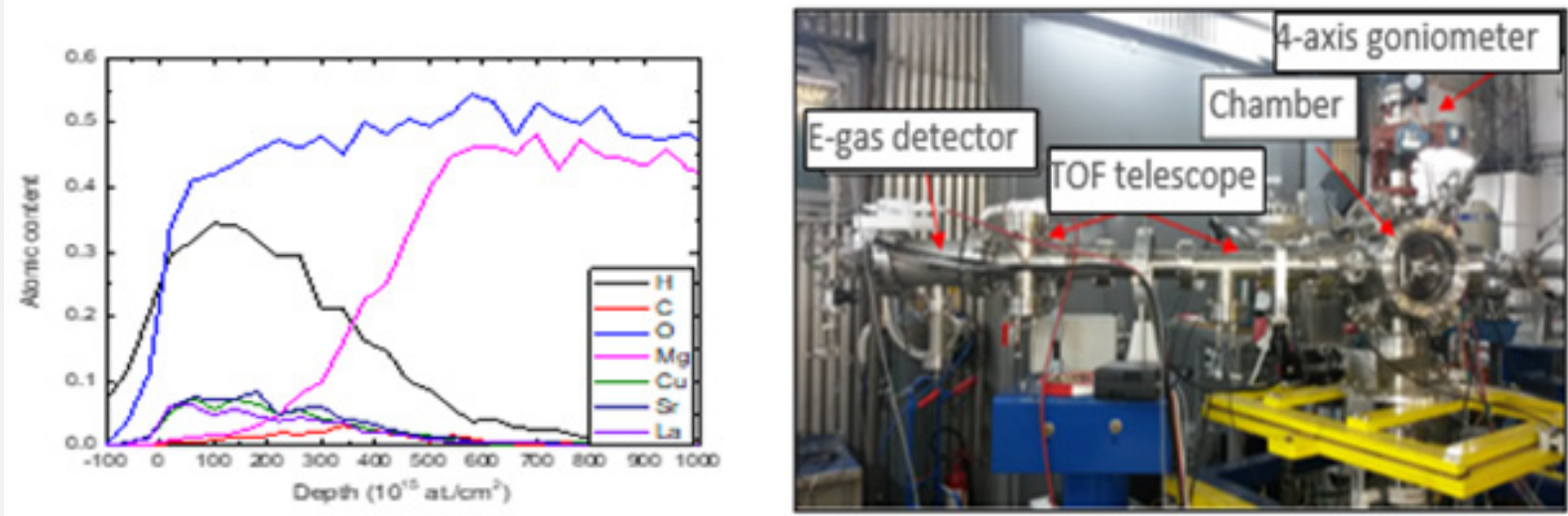

Figure 6(a): Atomic percentages with depth profiles of all elements in the sample (thin LSCO film deposit on $\mathrm{MgO})$, and TOF- ERDA setup at IRB.
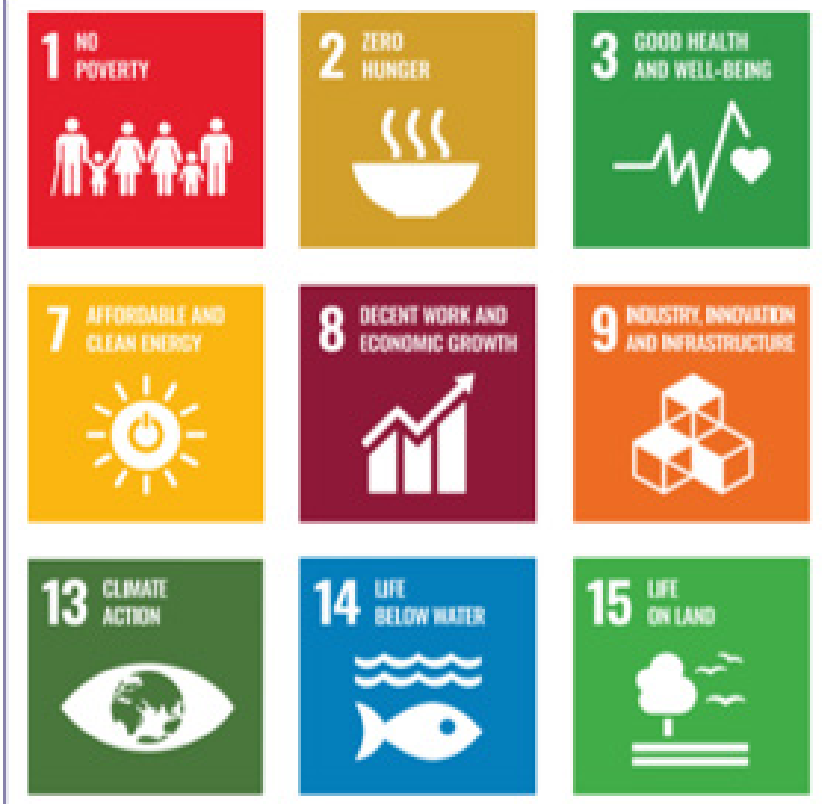
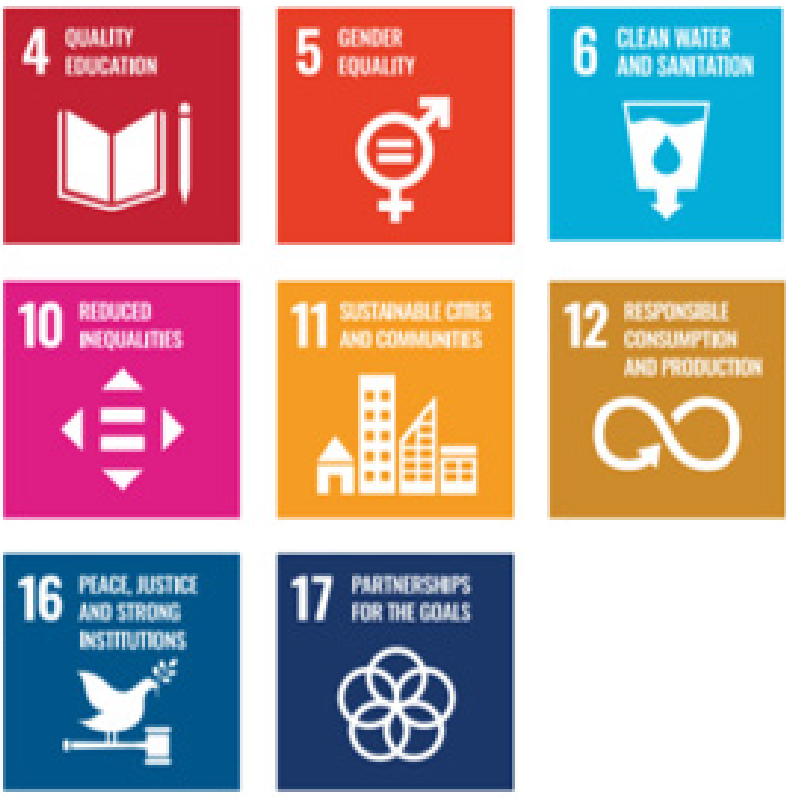

Figure 6(b): UN Sustainable Development Goals. 


\section{Conclusion}

Standardization is identified in Horizon 2020 as one of the innovation-support measures by bridging the gap between research and the market and helping the fast and easy transfer of research results to the European and international market. The research community acknowledges this - a recent study shows nearly three-quarters (73\%) of FP6 and FP7 project coordinators who included standards in their previous projects said that they would be willing to address standardization again (https://www. cencenelec.eu/research/tools/ImportanceENs/Pages/default. aspx).

Under what circumstances would it make sense to try aligning the current practices to those explained in the standard? As you can see, ISO 56002:2019 Innovation process as well as Sage process are different from the innovation process in research and educational organisations, depicted in Figure $1 \& 2$. Not only that the outcome in valuable results is different but also actions in process are more product development then innovation management oriented From the Sage's process is clear that R\&D Insights and Ideas are only at the beginning of the process and the rest of the process is pure product development process. Although, at the end of the day we are creating different innovative values, the process, and the standard should be efficiently generic to apply on both, business-oriented companies and research entities. The most crucial components of innovation management like cooperation and innovation assessment are explained in separate documents: ISO 56003, Innovation Management Collaborative Partnerships, and ISO/TR 56004, Innovation Management Assessment, but the principles of product development orientation to create value out of innovation stays in both. Nevertheless, the steps in the process that will explain when to move forward, and when to stop with an idea, are missing. Those decision points are connected with a creation of a responsible and acceptable invention. The ISO 56002:2019 is unfortunately not taking us there, not only because of the missing explanations but also because the ideas of responsible and acceptable inventions are not incorporated in the standard.

Today, without such approach and without considering at least UN Sustainable Development Goals, Figure 6, we cannot count on long term sustainable innovation that will bring back value to the organisations. On the other hand, in the PAS 440:2020 Responsible innovation - Guide (https://www.bsigroup.com/
en-GB/about-bsi/media-centre/press-releases/2020/april/ first-corporate-governance-guide-for- sponsible-nnovation/), we may find everything in one document including the responsible collaborations, assessment and even questions to ask about innovation's benefits and risks at the end of the document. Alice de Casanove, Chair of the ISO technical committee, who developed the standards, said that effective innovation management allows organizations to really flourish, by leveraging the knowledge and creativity of their own people and those they collaborate with. But today, the people knowledge and creativity cannot be used without considering the greater good, the good for the whole community and humanity. The future depends on that, and we can go forward only with good practices in innovation management, enjoying in new products, services and business models knowing that they were made in a responsible way just like scientist are doing new discoveries in their research.

\section{Acknowledgment}

Author acknowledge support by the HORIZON 2020 Project RADIATE under the Grant Agreement 824096.

\section{References}

1. ISO 56000, Innovation Management System - Fundamentals and vocabulary, preview

2. ISO 56002, Innovation Management System - Guidance

3. BS ISO 26000:2010, Guidance on social responsibility, preview

4. https://sageproductsglobal.com/innovation-landing-page/

5. PAS 440 Responsible Innovation - Guide.

6. Ajibade, Patrick (2018) Technology Acceptance Model Limitations and Criticisms: Exploring the Practical Applications and Use in Technologyrelated Studies, Mixed-method, and Qualitative Researches. Library Philosophy and Practice (e-journal) 1941.

7. European Union (2012). Responsible Research and Innovation Europe's ability to respond to societal challenges. Luxembourg: EU.

8. United Nations. Sustainable Development Goals.

9. European Political Strategy Centre (2016) Opportunity Now: Europe's Mission to Innovate. EPSC Strategic Notes.

10. Tait J (2017) From responsible research to responsible innovation: Challenges of implementation. Innogen Institute, University of Edinburgh, Old Surgeons Hall, High School Yards, Edinburgh. IET Digital Library Source 1(1): 7-11. 
This work is licensed under Creative Commons Attribution 4.0 License

DOI: 10.19080/ASM.2020.05.555671
Your next submission with Juniper Publishers will reach you the below assets

- Quality Editorial service

- Swift Peer Review

- Reprints availability

- E-prints Service

- Manuscript Podcast for convenient understanding

- Global attainment for your research

- Manuscript accessibility in different formats

( Pdf, E-pub, Full Text, Audio)

- Unceasing customer service

Track the below URL for one-step submission https://juniperpublishers.com/online-submission.php 